\title{
Statistical Analysis of the Effects of Barking on Growth Potential in Xishuangbanna Area
}

\author{
Zhao Yueshu ${ }^{1}$, Tang Yin ${ }^{1, *}$, and Xue Xiaoming ${ }^{1}$ \\ ${ }^{1}$ Criminal Science and Technology Department, Nanjing Forest Police Academy, China
}

\begin{abstract}
Xishuangbanna is the most important tropical rainforest region in southwestern China, with important ecological and economic value. In order to obtain the huge economic benefits of planting Pu'er tea, the local people often use the method of 'annular barking' for the trees suitable for planting tea trees, so that the tea trees can absorb more nutrients and thus obtain higher economic benefits. In this paper, random sampling method is used to collect data of 12 species of trees totaling 1753 samples in Xishuangbanna where cases of barking happen frequently. By collecting the data such as the year of barking, the growth environment of trees and the growth potential of trees, using linear regression analysis, a regression equation for the tree growth potential and the year of the barking. Through analysis, it is found that the growth potential of the barked trees is negatively correlated with the years after being barked, and the regression equation for the relationship between survival rate and years after being barked is: $\mathrm{Y}=46.366-8.289 \mathrm{x}$. The conclusion of this study will provide evidence of the tree damage and deaths caused by barking for forest police in Xishuangbanna, and provide strong theoretical support for the effective fight against criminals.
\end{abstract}

\section{Introduction}

Located in the south-western border of China, Yunnan is one of the important birthplaces of human civilization. It has various types of climate and abundant plant resources. Known as the "plant kingdom", Yunnan is a collection of plants from tropical, subtropical to temperate and even frigid zones $^{[1]}$. Yunnan Xishuangbanna Dai Autonomous Prefecture is an important producing area of Pu'er tea. In order to pursue economic benefits and obtain huge profits from tea planting, the local people often use the method of "annular barking" for the wild trees suitable for the growth of tea trees. The local forest police needs to identify the degree of damage to the trees and whether it can be fatal in the process of investigating such cases. However, there is no scientific argument for whether the barking can cause the trees to die, resulting in insufficient evidence for the case and high rate of withdrawal. It has seriously hindered forest police to crack down on crimes against forest resources.

In recent years, when the country pays great attention to ecological construction, the health status of landscaping tree species and ancient trees has attracted more attention. A related evaluation system has been established to classify the health status of garden trees into healthy, inferior-healthy, moderate growth, poor growth, badly poor growth. There are several ways such as using PICUS-tomograph diagnosis device, gray correlation analysis, and chi-square test to detect the health state of ancient trees. Zhang Lijuan ${ }^{[2]}$ firstly carried out the gray correlation aging evaluation of the ancient Fragrant Camphor Trees in the villages and towns of Hunan Province, providing accurate data support and technical advice for the protection of ancient and famous trees; Wan Shaoxia ${ }^{[3]}$ used the annular barking technology to bark fruit trees, as to block nutrient transport, promote flower bud formation, and improve the rate of fruits. However, the comprehensive evaluation system for the effects of annular barking on tree growth with statistical methods and the study of the death cycle of trees after being barked are not mentioned.

Therefore, based on the research of tree health assessment, this paper uses statistical methods and linear regression analysis to evaluate the growth potential of trees after being barked. It has certain advancement in technology and can provide standards of qualitative determination and punishment judgments for forest police in practice. It has important practical significance for protecting China's forest resources, maintaining ecological security management and improving the basic working ability of relevant law enforcement agencies.

\section{Basic concept}

\subsection{Concept and role of bark}

\footnotetext{
*Corresponding author: 287079145@qq.com
} 
The bark is a general term for various tissues and other components outside the xylem such as trunks and branches ${ }^{[4]}$. The phloem in the bark is a very important tissue in the bark, and tissues, known as catheters, are piped in the phloem. The purpose of the catheter is to transport the photosynthate of the leaves, transporting the organic matter produced by the leaves to the roots and parts; the bark also protects the trees, resists mechanical damage, resists cold and heat and prevents pests and diseases, and protects trees from external damage. Therefore, the bark plays a very important role in the life activities of plants. The large-scale annular barking or barking of the trunk is equivalent to stripping the full circle of phloem, which hinders the plant's photosynthate from being transported smoothly to the roots of the plants, which may lead to the death of the whole plant ${ }^{[5]}$.

\subsection{Tree growth potential}

Growth potential refers to the degree of growth and development of plants and is an objective reflection of crop vigor. However, there is no clear definition of crop growth potential and there is no standardized algorithm. The total number of growth branches is measured by the number of branches, the average length, the thickness, the degree of filling, the direction of growth, and the color of the branches of the stem, sometimes determined by the growth rate of the early shoots. In production, the growth of the latest shoots of the canopy is often used as one of the indicators to judge the vitality of the tree. The growth of trees is influenced by many factors such as tree species, varieties, trees themselves, outcomes, soil fertility, water management and pruning ${ }^{[6]}$.

According to the State Forestry Administration's "Ancient Tree Identification Standards", the growth potential of trees is divided into four grades according to the growth of leaves, branches and trunks: normal, debilitated, endangered and dead. The grading standards are shown in Table 1 .

Table 1. Grading standard

\begin{tabular}{|c|c|c|c|}
\hline \multirow{2}{*}{$\begin{array}{l}\text { Growth } \\
\text { potential }\end{array}$} & \multicolumn{3}{|c|}{ Grading standards } \\
\hline & Leaves & Branches & Chunk \\
\hline Normal & $\begin{array}{l}\text { Ratio of normal } \\
\text { leaves: }>95 \%\end{array}$ & $\begin{array}{l}\text { Branches grow normally, no } \\
\text { necrosis, many new branches }\end{array}$ & $\begin{array}{c}\text { Chunk basically intact, no } \\
\text { necrosis }\end{array}$ \\
\hline Debilitated & $\begin{array}{c}\text { Ratio of normal leaves: } \\
95 \% \sim 50 \%\end{array}$ & $\begin{array}{l}\text { Some of braches dead, few } \\
\text { new branches }\end{array}$ & Parts of chunk damaged \\
\hline Endangered & $\begin{array}{c}\text { Ratio of normal } \\
\text { leaves: }<50 \%\end{array}$ & $\begin{array}{l}\text { Most branches dead, few new } \\
\text { branches }\end{array}$ & Most parts of chunk dead \\
\hline Dead & All the leaves dead & All the branches dead & All bark dead \\
\hline
\end{tabular}

In this paper, 12 kinds of local tree species often involved in the case are used as the main research objects. Using basic methods of tree health assessment and based on data such as tree species, growth environment, years after being barked and tree growth potential, with observing method, correlation analysis method, sampling inference method and regression analysis, based on large sample data (1746), the author draws the relationship table of growth potential and years after being barked, finds the relationship between growth potential of trees and the years of perforation, obtains the influence of stripping on plants' health, the degree of damage and the direct impact on tree growth potential. Finally, the evaluation index system of damage degree of barked trees is constructed.

\section{Data source and analysis}

\subsection{Data source}

The data used in this study were collected from 12 species of debarked trees collected in Xishuangbanna Dai Autonomous Prefecture, totaling 1746 tree samples. During the data collection process, instruments such as GPS, theodolite, altitude meter, altimeter, and slope were used according to the survey criteria for each wood. The 12 kinds of trees are: Schima superba (274),
Cinnamomum camphora (L.) presl (354), Quercus acutissima (258), small Castanopsis hystrix (116), Castanopsis hystrix (142),Castanopsisfargesii(127), Castanopsismekongensis A.Camus (142), Quercus glauca Thunb. (76), Machilus pingii Cheng ex Yang (107), Betula alnoides (55), Wendlandia tinctoria (53), Phoebe sheareri (42).

\subsection{Data analysis}

Data such as tree species, growth location, growth surrounding environment, tree species, tree age, tree height, DBH, crown width, growth potential and growth environment were collected and made into Excel spreadsheets, and statistical analysis was performed using spss Statistics 19.0 and Excel.

\subsubsection{Excel statistics on survival rate of 12 species of trees}

After the introduction of the tree growth potential grading standard, the survival rate was introduced as a quantitative criterion for determining whether the tree died or not. The survival rate in this study refers to the ratio of the normal growth, absent of endangerment and death, ie, the ratio of normal and debilitating plants to the total trees. Tree survival refers to the fact that the trees 
grow well, the normal leaf volume is more than $50 \%$, the trunk does not necrotic, and most of the branches are intact, with branches of trees. Table 2 shows the relationship between 12 species of tree survival rates and the years of after being annular barked:

Table 2. Statistics on survival rate of 12 species of tree

\begin{tabular}{cccccc}
\hline Tree species & \multicolumn{5}{c}{ Years after being barked } \\
\cline { 2 - 5 } Schima & $\mathbf{2}$ years & $\mathbf{3}$ years & 4 years & $\mathbf{5}$ years & 6 years \& more \\
Camphor & $17.65 \%$ & $8.26 \%$ & $12.70 \%$ & $8.70 \%$ & $2.50 \%$ \\
Oak & $58.33 \%$ & $26.40 \%$ & $10.59 \%$ & $0.88 \%$ & $0.00 \%$ \\
Small Castanopsis hystrix & $85.71 \%$ & $18.18 \%$ & $1.69 \%$ & $4.29 \%$ & $5.71 \%$ \\
Castanopsis hystrix & 0 & $0.00 \%$ & $0.00 \%$ & 0 & $0.00 \%$ \\
Castanopsis & $40.00 \%$ & $32.00 \%$ & $20.00 \%$ & $2.00 \%$ & $0.00 \%$ \\
Mekong Castanopsis & $0.00 \%$ & $7.04 \%$ & $9.68 \%$ & $66.67 \%$ & $0.00 \%$ \\
Cyclobalanopsis & $44.44 \%$ & $30.43 \%$ & $16.67 \%$ & $0.00 \%$ & $0.00 \%$ \\
Machilus & $0.00 \%$ & $0.00 \%$ & $0.00 \%$ & 0 & $0.00 \%$ \\
Betula alnoides & $25.00 \%$ & $11.76 \%$ & $0.00 \%$ & $0.00 \%$ & $5.56 \%$ \\
Wendlandia tinctoria & $40.00 \%$ & $20.00 \%$ & $7.14 \%$ & $0.00 \%$ & 0 \\
Phoebe sheareri & $100.00 \%$ & $11.11 \%$ & $14.29 \%$ & $50.00 \%$ & $0.00 \%$ \\
Average survival rate & $37.80 \%$ & $13.97 \%$ & $8.87 \%$ & $11.05 \%$ & $1.15 \%$ \\
\hline
\end{tabular}

All the data samples (1746) of the 12 species will be summarized and the relationship between the overall tree growth potential and the years after being annularly barked in Xishuangbanna area will be obtained.
Table 3 shows the average survival rate of the 12 trees in five years and the overall tree survival rate. From this table, the average survival rate of the trees in the Xishuangbanna area after being barked is obtained.

Table3. Statistics on average survival rate of trees after years of being barked

\begin{tabular}{cccccc}
\hline Years after being barked & Normal & Endangered & Dead & Total & Survival rate $(\%)$ \\
\hline 2 years & 52 & 45 & 42 & 139 & 37.41 \\
3 years & 100 & 177 & 386 & 656 & 15.08 \\
4 years & 31 & 60 & 294 & 385 & 8.05 \\
5 years & 12 & 8 & 279 & 299 & 4.01 \\
6 years \& more & 4 & 13 & 250 & 267 & 1.5 \\
Total & 199 & 303 & 1244 & 1746 & 11.35 \\
\hline
\end{tabular}

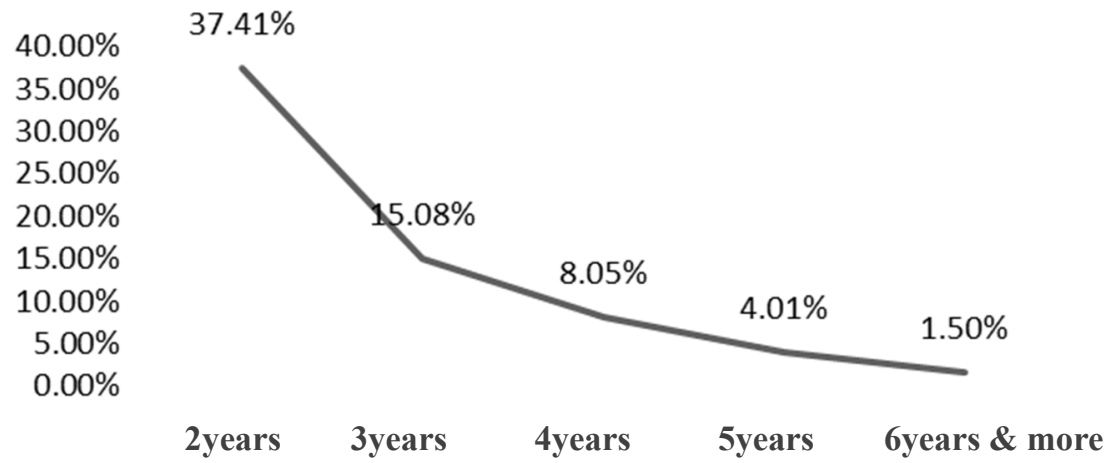

Fig. 3 Line chart of survival rate of trees after being barked

The relationship between survival rate of the barked trees and different years after being barked is shown in Figure 3. From this, the overall trend of the years after being barked and survival rate can be seen, and the survival rate of the barked trees is generally reduced with the increase of the years after being barked. 


\subsubsection{Spss regression analysis}

In statistics, regression analysis refers to a statistical analysis method that determines the quantitative relationship between two or more variables in an existing relationship ${ }^{[7]}$. In the present study, through the previous statistical analysis, it has been found that there is a negative correlation between tree survival rate and the years after being barked. In order to quantify the statistical results and obtain more scientific conclusions, linear regression analysis is introduced here. With the help of spss19.0 Software, through linear modeling, linear regression equations are drawn to reflect the relationship between tree survival rate and the year of being barked. At the same time, the calculated regression equation can be used to predict the relationship between the survival rate of the trees in the whole area of Xishuangbanna after being barked and the year of the barking.

Regression analysis was performed on the relationship between tree survival rate and the barking year using spss19.0 software. Table 4 shows the output of spss 19.0:
Table 4. SPSS model summary

\begin{tabular}{ccccc}
\hline \multicolumn{5}{c}{ Model summary } \\
\hline & & & Adjust & Standard error \\
Model & $\mathrm{R}$ & R square & Rsquare & estimate \\
1 & $0.906^{\mathrm{a}}$ & 0.820 & 0.760 & 7.082 \\
\hline
\end{tabular}

a. predictive variable: (constant), $\mathrm{x}$

In the result output of spss19.0, it is also possible to report the $\mathrm{R}$ square, the $\mathrm{F}$ test value and the $\mathrm{T}$ test value. The $\mathrm{R}$ square is also called the coefficient of determination of the equation, which indicates the degree of interpretation of the variable $\mathrm{X}$ to $\mathrm{Y}$ in the equation. The value of the $\mathrm{R}$ square is between 0 and 1 , the closer to 1 , the stronger the ability of $\mathrm{X}$ to interpret $\mathrm{Y}$ in the equation. The $\mathrm{R}$ square is usually multiplied by $100 \%$ to represent the percentage of the regression equation that accounts for the change in $\mathrm{Y}$. The $\mathrm{R}$ square in the table is 0.906 , which indicates that the model of the equation is very good, and the calculated results are also reliable, and the relationship between the survival rate and the barking year can be calculated more accurately.

Table 5. Anova

\begin{tabular}{ccccccc}
\hline \multicolumn{7}{c}{ ANOVA $^{\mathrm{b}}$} \\
\hline & Model & Sum of squares & df & Mean square & F & Sig. \\
& Regression & 687.075 & 1 & 687.075 & 13.700 & $0.034^{\mathrm{a}}$ \\
& Residual & 150.451 & 3 & 50.150 & & \\
& Total & 837.527 & 4 & & & \\
\hline
\end{tabular}

a. predictive variable: (constant), $\mathrm{x}$

b. dependent variable: $y$

Table 6. Coefficient

\begin{tabular}{|c|c|c|c|c|c|c|}
\hline \multicolumn{7}{|c|}{ Coefficient } \\
\hline \multirow{2}{*}{\multicolumn{2}{|c|}{ Model }} & \multicolumn{2}{|c|}{ Non-standard coefficent } & \multirow[t]{2}{*}{ Standard coefficent } & \multirow{2}{*}{$\mathrm{t}$} & \multirow{2}{*}{ Sig. } \\
\hline & & B & Standard error & & & \\
\hline \multirow{2}{*}{1} & (constant) & 46.366 & 9.501 & & 4.880 & 0.016 \\
\hline & Years after being barked & -8.289 & 2.239 & -0.906 & -3.701 & 0.034 \\
\hline
\end{tabular}

a. dependent variable: survival rate

The $\mathrm{F}$ test is output through the table of variance analysis, and it is tested whether the linear relationship of the regression equation is significant by the significance level. In general, the significance level makes sense when it is above 0.05 . The Sig value corresponding to the $\mathrm{F}$ value in Table 5 is less than 0.05 , so the equation can be considered to be meaningful, and the tree survival rate is significantly correlated with years after being barked. According to Table 6, the standard coefficient is -0.906 , and the resulting regression equation is:

$$
\begin{gathered}
Y=46.366-8.289 x \\
Y: \text { survival rate (\%) } \\
X: \text { the barking year (year) }
\end{gathered}
$$

While the regression equation is obtained, the trees in the Xishuangbanna area can be taken into the equation and the survival rate can be calculated. The growth potential can be calculated by regression equation after the barking year is obtained, and other factors considered, such as tree species, growth environment, etc., the growth potential can be more accurately determined.

\section{Conclusion}

In this study, 1746 tree data samples were collected and statistical analysis was performed using Excel software. It was found that the growth potential was most affected by the years after being barked. The statistical analysis of 
the statistical results was carried out using spss 19.0 software. It was found that there was a significant correlation between tree survival rate and the years after being barked, and a linear regression equation was obtained: $Y=46.366-8.289 x$, (Y: trees Survival rate (\%); $\mathrm{x}$ : the years after being barked, and the survival rate of the tree after being barked was negatively correlated with the years after being barked. As the years after being barked increased, the survival rate is getting lower and lower.

Based on the study on 12 species of trees, the average survival rate after two years of being barked was $37.41 \%$, which is $>$ survival rate after three years $15.08 \%>$ survival rate after four years $8.05 \%>$ survival rate after five years $4.01 \%>$ survival rate after six years $1.50 \%$. According to the sample capacity of 1746 , after two years of being barked, about 653 trees survived. After three years, about 263 trees survived. After four years, about 140 trees survived. After five years, about 70 trees survived. After six years, about 26 trees survived. There are almost no trees survived after more than 6 years, taking into account the errors and objective factors such as shallow cutting edges during cutting, artificial restoration at the later stage, and individual tree growth characteristics. Therefore, it can be determined that the local trees are almost completely dead after 6 years of being barked, and the remaining trees that are still alive will eventually die as the years going.

\section{Peroration}

This study is based on statistics, with the data collected in the Xishuangbanna area. The conclusion can be initially used to resolve cases that the forest police cannot file and investigate for the tree will not immediately die after being barked. Further research on other factors affecting the growth potential of the barked trees is needed.

\section{Fund projects:}

the Fundamental Research Funds for the Central Universities（LGYB201809）

\section{References}

1. China Travel Guide Editorial Board, Xishuangbanna, China, Zhong Hua Book Company, M. 96(2001).

2. Zhang Lijuan, Analysis of Morphological Appearances and Physiologal Characteristics in Old Camphor Trees having Different Growth Potentials, China, Nanjing Agriculture University. D.20(2011).

3. Wan Shaoxia, Ring Peeling can Improve Fruit Setting Rate of Vigorous and Fruitless Fruit Trees, China, Hebei Agricultural Science and Technology. J.3, 27(1999).

4. Xue Xiaoming, Chen Yunxia, Basis of Wood Identification, China, China Forestry Publishing House. M. 71(2018).
5. Shi Jingjing, Lei Yuancai, Zhao Tianzhong, Advances in Research on Sampling Survey Techniques and Methods of Forest Resources, China, Forestry Science Research. J.1, 105-112(2009).

6. Lu Bin, Chen Xuenian, Li Zhiyi, The Relationship between Peroxidase Activity and Growth Vigour of Orange CV. Xianfeng Grafted on Different Root stocks, China, Southwest China Journal of Agricultural Sciences. J.2, 64-68(1999).

7. Du Jiaju, Chen Zhiwei, Path Analysis Using SPSS Linear Regression, China, Biological Bulletin.J.2,8-10(2010). 